\title{
Molecular Diagnosis of Viral Respiratory Infections
}

\author{
Shu Zhang $\cdot$ Wenhong Zhang $\cdot$ Yi-Wei Tang
}

Published online: 1 February 2011

(C) Springer Science+Business Media, LLC 2011

\begin{abstract}
In clinical practice, a rapid and accurate identification of pathogens causing viral respiratory tract infections can be problematic because of nonspecific clinical presentations, lack of rapid and sensitive tests, and the emergence of new and mutating viral pathogens. Nucleic acid-targeted molecular techniques are increasingly being used to provide high sensitivity and specificity, short test turnaround time, and automatic and high-throughput processing. In-house and commercially available molecular methods have been developed to qualitatively and quantitatively detect and identify a single or a panel of clinically encountered respiratory tract viruses in a single reaction. Molecular techniques are being gradually introduced in routine laboratory diagnosis of viral respiratory tract infections. However, their performance characteristics and limitations must be clearly understood by both laboratory personnel and clinicians to ensure proper utilization and interpretation.
\end{abstract}

\section{S. Zhang $\cdot$ Y.-W. Tang}

Department of Pathology, Vanderbilt University Medical Center, Nashville, TN 37232, USA

Y.-W. Tang

Department of Medicine, Vanderbilt University Medical Center, Nashville, TN 37232, USA

\section{S. Zhang $\cdot$ W. Zhang}

Department of Infectious Diseases, Huashan Hospital, Fudan University,

Shanghai 200040, China

\section{Y.-W. Tang $(\bowtie)$}

Molecular Infectious Disease Laboratory,

Vanderbilt University Hospital,

4605 TVC,

Nashville, TN 37232-5310, USA

e-mail: yiwei.tang@vanderbilt.edu
Keywords Respiratory viruses · Infectious diseases · Molecular methods · Nucleic acid amplification tests . Real-time polymerase chain reaction · Microarrays $\cdot$ Mass spectrometry Target-enriched multiplexing polymerase chain reaction - Loop-mediated isothermal amplification . Multiplex ligation-dependent probe amplification . Sequence-independent single-primer amplification

\section{Introduction}

Viral respiratory infections have been increasingly recognized as main contributors to hospitalizations and mortality in all age groups worldwide. Appropriate management of patients with viral respiratory illnesses requires rapid and accurate identification of the etiologic agent of these infections. Unfortunately, identifying a specific viral respiratory pathogen in these infections can be problematic and elusive for several reasons, such as the wide range of potential viral pathogens that can cause similar clinical manifestations, the insensitivity of conventional laboratory diagnostic tests, and the presence of new and mutating viral pathogens. Rapid detection and identification of viral pathogens causing respiratory tract infections has been demonstrated to significantly decrease the duration of hospitalization and reduce management costs, and to avoid additional laboratory testing and unnecessary antibiotic use; additionally, rapid detection and identification help to guide specific antiviral therapy and appropriate isolation precautions [1,2].

The major causes of viral respiratory diseases in children and adults are influenza virus (Flu) A and B, parainfluenza virus type 1 (PIV1), PIV2, PIV3, respiratory syncytial virus (RSV), adenoviruses (AdV), and enteroviruses (EnV). However, as a result of the application of novel detecting 
techniques, other viruses have been added to the list of significant viral respiratory pathogens: coronaviruses $(\mathrm{CoV})$, human metapneumovirus (hMPV), human rhinoviruses (hRhV), human bocaviruses (hBoV), PIV4, the newly discovered parvovirus types 4 and 5 , mimivirus, respiratory polyomaviruses, and xenotropic murine leukemia virusrelated virus (XMRV). Some of these emerging pathogens (identified since 2000) can cause pandemic or fatal respiratory infections, including severe acute respiratory syndrome (SARS) CoV, avian influenza viruses (H5N1, H7N7, and H7N3), and swine influenza viruses (H1N1); furthermore, the clinical significance of others is still not known. Indeed, all of the viruses mentioned are associated with similar and atypical clinical presentations and infect both upper and lower respiratory tracts, which makes it very difficult for clinicians to distinguish the causative pathogen without a laboratory diagnosis.

Traditionally, because of its excellent specificity, virus isolation from respiratory secretions and culture testing remains the gold standard for laboratory diagnosis of most viral respiratory infections. Viral culture is most useful in highly febrile patients who have been ill only 2-3 days. Recovered viral strains are useful for further characterization and antiviral susceptibility testing [3]. However, viral culture is technically demanding, relatively insensitive compared with serological tests and PCR, and time consuming even incorporated with shell vial culture techniques. Some viral pathogens $(\mathrm{eg}, \mathrm{hBoV})$ are not culturable, and cultivation of highly contagious viral pathogens (eg, SARS CoV) in routine diagnostic laboratory is dangerous to the laboratory staff.

Various rapid antigen tests have been the mainstay of the clinical laboratory for diagnosing viral respiratory infections. Several formats, led by immunofluorescent antibody assay (IFA), direct fluorescent antibody assay (DFA), and enzyme immunoassay (EIA), are available for detecting and even subtyping main respiratory viruses (eg, Flu and RSV) within a short time [3]. It should be kept in mind that falsenegative rapid antigen results can be expected, and should not be interpreted as excluding the possibility of infection caused by the tested viral pathogen. With low sensitivities, rapid antigen tests were usually relegated to point-of-care testing for influenza in defined settings. Serology-based procedures have been primarily in surveillance and epidemiology studies, whereas their applications in diagnosis of viral respiratory diseases have been limited. A single serum sample to detect viral-specific $\operatorname{IgG}$ is not useful for diagnosis. Instead, paired acute- and convalescent-phase sera, collected at least 10 days apart, are needed to detect a fourfold or greater increase in serum antibody levels indicative of a recent infection.

Technical advances in molecular biology have significantly expanded and improved the capabilities of diagnostic micro- biology. Nucleic acid amplification tests led by polymerase chain reaction (PCR) were developed for most respiratory viruses by the end of the decade; today, they are emerging to be used in the routine clinical laboratory as the preferred method for viral diagnostic testing, either as an adjunct to or a replacement for another method. Real-time technology and the ability to perform multiplex testing have facilitated this emergence. Molecular techniques have found their niches in laboratory diagnosis of viral respiratory tract infections by providing rapid and highly sensitive tools to detect and identify the causal pathogens. They also allow assessment of the impact of a wider array of potential pathogens on viral respiratory infections than previously possible, and targetspecific (multiplex) approaches have proved feasible for enhanced broad-spectrum respiratory virus diagnosis. A wide range of both target and signal amplification nucleic acid amplification methods could be applied to respiratory virus detection. The target amplification technique has the advantage of sensitivity above signal amplification, but the latter may be simpler and less laborious for high throughput. In this review, we focus on commercially available molecular assays, and discuss the performance characteristics required to successfully implement molecular methods for routine diagnosis of viral respiratory infections.

\section{Commercially Available Molecular Assays for Specific Respiratory Virus Detection}

Current molecular techniques for detection of respiratory viruses include real-time PCR, target-enriched multiplexing PCR (TEM-PCR), nucleic acid sequence-based amplification (NASBA), sequence-independent single-primer amplification (SISPA), loop-mediated isothermal amplification (LAMP), multiplex ligation-dependent probe amplification (MLPA), solid and liquid microarrays, and mass spectrometry. Multiplex PCR with solid or suspension microarrays is the most recent diagnostic advance. Principles and formats of these molecular techniques have been well reviewed recently by Fox [4•] and $\mathrm{Wu}$ et al. [5•]. In addition to numerous user-developed, research-oriented molecular methods, several commercial devices have been produced for routine clinical diagnostic use to detect and identify different respiratory viruses and subtypes, including Flu A, A subtype H1, A subtype H3, A subtype H5, and B; RSV A and B; PIV 1-4; AdV A, B, C, and E; and EnV A, B, C, and D. In particular, they also can identify newly discovered viral respiratory pathogens, such as $\mathrm{H} 5 \mathrm{~N} 1$ avian influenza virus; $\mathrm{H} 1 \mathrm{~N} 1$ swine influenza virus; $\mathrm{hRhV} \mathrm{A}, \mathrm{B}$, and $\mathrm{C}$; hMPV A and B; hBoV 1-4; CoV NL63, OC43, HKU1, 229E, and SARS. Table 1 provides a brief description of commercial diagnostic devices currently available in the United States for the detection of respiratory viruses. 
Table 1 Current commercially available multiplexed molecular assays for diagnosis of viral respiratory infections

\begin{tabular}{|c|c|c|c|c|}
\hline Main commercial assays & Viruses covered & $\begin{array}{l}\text { Detection } \\
\text { platform }\end{array}$ & $\begin{array}{l}\text { Clinical } \\
\text { application }\end{array}$ & Comments (key references) \\
\hline $\begin{array}{l}\text { FilmArray respiratory } \\
\text { pathogen panel (Idaho } \\
\text { Technology, Salt Lake } \\
\text { City, UT) }\end{array}$ & $\begin{array}{l}\text { AdV, CoV, Flu-A, Flu-B, } \\
\text { hBoV, hMPV, hRhV, PIV 1- } \\
\text { 4, and RSV }\end{array}$ & Solid array & $\begin{array}{l}\text { Detection, } \\
\text { quantification, } \\
\text { and typing }\end{array}$ & $\begin{array}{l}\text { Integrated and closed system; } \\
\text { also covers four bacterial pathogens }[5 \bullet]\end{array}$ \\
\hline $\begin{array}{l}\text { Infiniti respiratory virus } \\
\text { panel (AutoGenomics, } \\
\text { Carlsbad, CA) }\end{array}$ & $\begin{array}{l}\text { AdV, CoV, EnV, Flu-A, Flu-B, } \\
\text { hMPV, hRhV, PIV 1-4, and } \\
\text { RSV }\end{array}$ & Solid array & $\begin{array}{l}\text { Detection, } \\
\text { quantification, } \\
\text { and typing }\end{array}$ & $\begin{array}{l}\text { Detection step by the Infiniti analyzer } \\
\text { is completely automatic [15] }\end{array}$ \\
\hline $\begin{array}{l}\text { MultiCode PLx } \\
\text { respiratory virus panel } \\
\text { (EraGen Biosciences, } \\
\text { Madison, WI) }\end{array}$ & $\begin{array}{l}\text { AdV, CoV, Flu-A, Flu-B, } \\
\text { hMPV, hRhV, PIV 1-4, and } \\
\text { RSV }\end{array}$ & $\begin{array}{l}\text { Suspension } \\
\text { array* }\end{array}$ & $\begin{array}{l}\text { Detection, } \\
\text { quantification, } \\
\text { and typing }\end{array}$ & $\begin{array}{l}\text { Universal beads used for detection use } \\
\text { EraCode sequences }[12,14,26]\end{array}$ \\
\hline $\begin{array}{l}\text { ProFlu }+(\text { Prodesse, } \\
\text { Waukesha, WI })\end{array}$ & Flu-A, Flu-B, and RSV & $\begin{array}{l}\text { Melting } \\
\text { temperature } \\
\text { analysis }\end{array}$ & $\begin{array}{l}\text { Detection and } \\
\text { typing }\end{array}$ & $\begin{array}{l}\text { Limited multiplex formats (triplex); } \\
\text { ProFlu+has received FDA clearance }[7,8]\end{array}$ \\
\hline ProParaflu+(Prodesse) & PIV $1-4$ & $\begin{array}{l}\text { Melting } \\
\text { temperature } \\
\text { analysis }\end{array}$ & $\begin{array}{l}\text { Detection and } \\
\text { typing }\end{array}$ & Limited multiplex formats $[5 \bullet]$ \\
\hline ProhMPV+(Prodesse) & hMPV A and B & $\begin{array}{l}\text { Melting } \\
\text { temperature } \\
\text { analysis }\end{array}$ & $\begin{array}{l}\text { Detection and } \\
\text { typing }\end{array}$ & $\begin{array}{l}\text { Limited multiplex formats (triplex); } \\
\text { ProhMPV+has received FDA clearance } \\
{[24 \cdot \bullet]}\end{array}$ \\
\hline $\begin{array}{l}\text { ResPlex II (Qiagen, } \\
\text { Valencia, CA) }\end{array}$ & $\begin{array}{l}\text { AdV, CoV (including SARS } \\
\text { CoV), EnV, Flu-A, Flu-B, } \\
\text { hBoV, hMPV, hRhV, PIV 1- } \\
\text { 4, and RSV }\end{array}$ & $\begin{array}{l}\text { Suspension } \\
\text { array }\end{array}$ & $\begin{array}{l}\text { Detection, } \\
\text { quantification } \\
\text { and typing }\end{array}$ & $\begin{array}{l}\text { Unique TEM-PCR permits multiple target } \\
\text { screening in single reaction without signifi- } \\
\text { cant loss in sensitivity [13•] }\end{array}$ \\
\hline $\begin{array}{l}\text { Seeplex RV/PB (Seegene, } \\
\text { Seoul, Korea) }\end{array}$ & $\begin{array}{l}\text { AdV, CoV, EnV, Flu-A, Flu-B, } \\
\text { hBoV, hMPV, hRhV, PIV 1- } \\
\text { 3, and RSV }\end{array}$ & $\begin{array}{l}\text { Gel } \\
\text { electrophoresis }\end{array}$ & $\begin{array}{l}\text { Detection and } \\
\text { typing }\end{array}$ & Dual-priming oligonucleotide system [5•] \\
\hline $\begin{array}{l}\text { xTAG respiratory virus } \\
\text { panel (Luminex } \\
\text { Molecular Diagnostics, } \\
\text { Toronto, Canada) }\end{array}$ & $\begin{array}{l}\text { AdV, CoV (including SARS } \\
\text { CoV), EnV, Flu-A, Flu-B, } \\
\text { hMPV, hRhV, PIV 1-4, and } \\
\text { RSV }\end{array}$ & $\begin{array}{l}\text { Suspension } \\
\text { array }\end{array}$ & $\begin{array}{l}\text { Detection, } \\
\text { quantification } \\
\text { and typing }\end{array}$ & $\begin{array}{l}\text { Target-specific primer extension used in } \\
\text { combination with universal detection beads; } \\
\text { xTAG respiratory virus panel has received } \\
\text { FDA clearance }[9 \cdot, 10,11,24 \bullet \bullet]\end{array}$ \\
\hline
\end{tabular}

$A d V$ adenovirus; $C o V$ coronavirus; EnV enterovirus; FDA Food and Drug Administration; Flu influenza virus; $h B o V$ human bocavirus; $h M P V$ human metapneumovirus; $h R h V$ human rhinovirus; PIV parainfluenza virus; $R S V$ respiratory syncytial virus; $S A R S$ severe acute respiratory syndrome; TEM-PCR target-enriched multiplexing polymerase chain reaction

*A new detection format is being sought

\section{Influenza Virus}

Despite the availability of vaccines, influenza virus remains the leading cause of acute respiratory infection outbreaks every year. Pandemics follow the emergence of a novel virus subtype with a new combination of the hemagglutinin (HA) or neuraminidase (NA) gene. Rapid antigen assays for the detection of influenza are commonly available, although negative results using these assays increase significantly with the increasing age of the patient. Real-time PCR or culture is necessary to avoid false-negative results in older patients. Molecular methods for detecting influenza viruses were described as early as 1991. Various targets have been used, including the matrix, HA, and NA genes. The first commercially available assay was the Hexaplex assay (Prodesse Inc., Waukesha, WI); it had an analytical sensitivity of 10 copies for influenza $\mathrm{A}$ and five copies for influenza B [6], and set the standard for the detection of influenza viruses. Since then, it has been developed and is now a Food and Drug Administration (FDA)-approved multiplex RT-PCR assay (Pro-Flu+; Prodesse Inc.) for detecting influenza A, influenza B, and RSV. According to the manufacturer, it has a clinical sensitivity and specificity of $100 \%$ and $93 \%$ for influenza $A$ and $98 \%$ and $99 \%$ for influenza B, respectively $[7,8]$. Another FDAapproved multiplex panel is the xTAG Respiratory Virus Panel (RVP) (Luminex Molecular Diagnostics, Toronto, Canada), which is capable of detecting 12 respiratory viruses and subtypes including influenza. This assay uses multiplex PCR and the Luminex x-MAP suspension array to have a reported clinical sensitivity of $100 \%$ for influenza A $[9 \cdot, 10,11]$.

In addition to these FDA-approved assays, several manufacturers have molecular assays available as analytic specific reagents (ASR) or research use only (RUO) kits, such as the MultiCode-PLx RVP (EraGen Biosciences, Inc., Madison, WI) and the ResPlex II Panel (Qiagen Inc., Valencia, CA). Their performance claims have been 
reported as similar to the xTAG RVP $[12,13 \cdot, 14]$. Automated solid film microarray systems for detection and identification of a panel of respiratory viruses are commercially available and are in clinical trials, including the Infiniti analyzer (AutoGenomics, Inc., Carlsbad, CA) [15] and the FilmArray (Idaho Technology Inc., Salt Lake City, UT) [5•]. In particular, the multiplex PCR tests have been reported to sentinel the appearance of emerging novel genotype and/or subtype of influenza A viruses, such as $\mathrm{H} 5 \mathrm{~N} 1$ avian influenza virus and $\mathrm{H} 1 \mathrm{~N} 1$ swine influenza virus [16-21]. A FLU-Plex-ID device, combining multilocus PCR amplification and mass spectrometry detection, has been developed by Ibis Biosciences (Carlsbad, CA) and is being validated in a clinical trial. This device covers and subtypes all varieties of Flu A subtypes and mutants with high sensitivity and specificity (unpublished observations).

\section{Respiratory Syncytial Virus}

RSV is the single most important respiratory viral pathogen in infants and young children, and is an important pathogen of respiratory disease in the elderly and high-risk adults. Rapid antigen assay in EIA format has been used for many years for RSV detection. Because of its good specificity and poor sensitivity, specimens with negative antigen results are routinely re-tested by culture. As with influenza, the Hexaplex assay was the first commercially available assay for RSV detection, with a clinical sensitivity of $91 \%$ and specificity of $99 \%$ in a mixed population of adults and children [22]. It has been redesigned into a multiplex RT-PCR format (Pro-Flu+) and received FDA clearance [7, 8]. Another FDA-approved molecular device, the xTAG RVP (Luminex), covers RSV as well. Both FDA-cleared devices have a much higher clinical sensitivity and specificity for RSV detection compared with conventional rapid antigen immunoassays, especially in immunocompromised adults [23]. Other RUO and ASR assays commercially available for RSV detection and RSV-A and B subgrouping include the MultiCode-PLx RVP from EraGen and the ResPlex II from Qiagen. It has been demonstrated that these multiplex RT-PCR-based molecular devices are the most sensitive method for the detection of RSV, regardless of the population tested. Moreover, specimens with low viral load in adults and immunocompromised patients are more likely to be antigen negative and RT-PCR positive [8].

\section{Parainfluenza Virus}

Human parainfluenza viruses contain four subtypes (PIV 14) that are associated with distinct clinical syndromes, age groups, and seasonality. PIV 1-3 are a related group of important human respiratory pathogens, especially in young children. PIV 4 is much less studied than PIV $1-3$, and generally appears to cause less severe respiratory illness. Relative to other common respiratory viruses, the PIV have been somewhat neglected in the laboratory. The culture is relatively insensitive and current diagnosis depends mainly on rapid antigen detection by DFA. A number of multiplex respiratory virus assays include PIV as targets. The only FDA-approved assay covering PIV is the xTAG RVP (Luminex) with a clinical sensitivity of $100 \%, 92 \%$, and $100 \%$ for PIV 1, 2, and 3, respectively [9•]. The MultiCode-PLx RUO assay (EraGen) has reported sensitivity of $85 \%$ to $90 \%$ [14], whereas the ResPlex II RUO assay (Qiagen) has a cross-reactiveness between PIV 1 and PIV 3 [13•]. The Pro-Paraflu+ assay (Prodesse) has been available as an RUO kit while multicenter clinical trials are under way with FDA submission.

\section{Adenoviruses}

At least $51 \mathrm{AdV}$ have been demonstrated to infect humans, and are grouped into six species A to F. Adenoviruses are common causes of self-limiting respiratory illnesses and outbreaks in immunocompetent children and US military recruits. They have been reported to cause severe, prolonged, and sometimes fatal illness in immunocompromised hosts. Most of the human adenoviruses causing respiratory diseases are found in species B, C, and E. Conventional diagnostic methods for respiratory adenoviruses infection include culture and rapid antigen detection by DFA. Molecular methods provide the most sensitive method for detecting AdV in clinical materials, although few validations and comparisons of different methods have been performed. One AdV molecular assay, which uses conventional PCR amplification followed by hybridization to probes in a 96-well microtiter plate, is available commercially from Argene (Sherley, NY) in RUO format. Three commercial multiplex PCR assays, the MultiCode-PLx assay (EraGen), the ResPlex II assay (Qiagen), and the xTAG RVP assay (Luminex) all detect AdV, but their performance is largely unknown. To date, the xTAG RVP assay is the only FDAapproved molecular test for detecting AdV from respiratory specimens with a clinical sensitivity of $78 \%$ [24••].

\section{Human Metapneumovirus}

Since its discovery in 2001, hMPV has been established as a significant respiratory etiologic agent in children and adults. Severe hMPV infections resulting in hospitalizations and intensive care unit admissions have been described in elderly adults with underlying conditions and in immunocompromised patients. hMPV infections can be diagnosed using a variety of approaches including serology, virus 
isolation, and antigen or nucleic acid detection. Available commercial molecular assays include the xTAG RVP assay (Luminex), the ResPlex II (Qiagen), the MultiCode-PLx RVP (EraGen), the Pro hMPV+ Real Time Assay RUO (Prodesse Inc.), and the Seeplex RV detection kit (Seegene Inc., Seoul, South Korea). The xTAG RVP assay is the only FDA-approved commercial multiplex assay for hMPV and has a sensitivity of $96 \%$ and a specificity of $98.6 \%$ [24••]. The Pro-hMPV+ assay had a clinical sensitivity of $95 \%$, according to the manufacturer. The sensitivity and specificity of the ResPlex II and MultiCode-PLx assays for detecting hMPV have not been determined. It has been reported that the MultiCode-PLx RUO assay is much more sensitive than the ResPlex II Panel RUO assay [13•, 14]; however, these reports suffered from low numbers of positive samples and lack of a comparator assay.

\section{Other Newly Discovered Viral Respiratory Pathogens}

Human rhinoviruses and coronaviruses were previously considered as conventional viruses associated with upper respiratory infections. However, more recently, they have been reported to have higher-than-expected rates in respiratory hospitalizations. Rhinoviruses were not considered to be clinically important by infectious disease clinicians until recently; they were reported to cause serious lower respiratory tract infections in young children, adults, and immunocompromised individuals. Although rhinoviruses can be detected by viral culture, most clinical laboratories did not provide rhinovirus diagnosis until recently; several in-house developed molecular assays showed sensitivities for rhinovirus detection of $85 \%$ using NASBA and $83 \%$ using RT-PCR [25]. Four recently introduced commercial multiplex assays - the ResPlex II assay (Qiagen), the MultiCode-PLx RVP assay (EraGen), the Seeplex RV assay (Seegene), and the xTAG RVP assay (Luminex) - cover rhinovirus as a target; however, only the xTAG RVP assay is approved by the FDA for rhinovirus detection, and was $100 \%$ sensitive and $91 \%$ specific in clinical evaluations $[24 \bullet \bullet$. Of note, there appear to be rhinoviruses not detected using these molecular methods or positive results that cannot be confirmed by culture, which implies that more sequence data from different rhinovirus serotypes and currently circulating strains are needed.

Five coronaviruses species-229E, OC43, SARS-CoV, NL63, and HKU1- have been described to cause human respiratory diseases. CoV OC43 and 229E have been associated with both upper and lower respiratory tract infection in a variety of settings, including nosocomial infections in high-risk immunocompromised children and hospitalized elderly patients. SARS-CoV, the causative agent of an outbreak of SARS worldwide from 2002 to 2003, has not been found to circulate in people since 2004 .
The other two new CoV species, NL63 and HKU1, were described in 2004 and 2005, respectively. A variety of molecular techniques including RT-PCR, NASBA, and LAMP have been applied for detecting CoVs. However, no available commercial assay is approved by the FDA for detecting $\mathrm{CoV}$ infection. The xTAG RVP assay (Luminex) covers all five CoVs, but the portion of detection and differentiation of CoVs has not been FDA cleared [24••]. Other multiplex PCR-based devices, including the MultiCode-PLx RUO assay (EraGen) and the ResPlex II assay (Qiagen), cover CoVs. The clinical sensitivities of the two assays await further investigation with adequate numbers of positive specimens [26].

Human bocavirus is a new virus that was discovered in 2005 using nonspecific large-scale molecular viral screening techniques. It has been reported that two genotypes of $\mathrm{hBoV}$ are circulating worldwide. Since the first publication, numerous studies have reported $\mathrm{hBoV}$ prevalences ranging from $2 \%$ to $19 \%$ in respiratory tract specimens from patients with acute respiratory symptoms. Bocaviruses have not yet been isolated in cell culture, and $\mathrm{hBoV}$ infections have been diagnosed exclusively by using molecular methods [27-29]. At the time of writing, there are no FDA-approved commercial tests for detection of $\mathrm{hBoV}$. The version 2 of the ResPlex II assay (Qiagen) and the xTAG RVP assay (Luminex) cover hBoV, but the performance awaits complete validations. After the analytical and diagnostic sensitivity and specificity of the $\mathrm{hBoV}$ assays are determined, the clinical relevance of positive $\mathrm{hBoV}$ results merits further investigation.

\section{Clinical Relevance of Molecular Diagnosis of Viral Respiratory Infections}

With the implementation of nucleic acid amplification tests, the capacities of laboratory diagnostic methods of viral respiratory infections have been significantly enhanced. Compared to conventional methods, molecular methods (especially those in multiplex formats) can simultaneously detect a panel of viral pathogens, thereby increasing diagnostic yield. It is important that molecular test results be interpreted correctly. A positive molecular test result indicated that targeted viral pathogen-specific nucleic acids were detected in the specimen submitted. Specifically for the viral respiratory pathogens, a positive molecular test result can indicate contamination, shedding, infection, or disease. Although quantitative information may be useful to differentiate the causal and the casual relationship, clinical manifestations and other laboratory test results in the complication of background diseases need to be combined before a definitive clinical diagnosis is reached.

Molecular methods are more sensitive and more rapid than conventional culture methods, which may translate into better 
medical outcomes due to more rapid administration of specific antiviral therapy, elimination of unnecessary antibiotic use, shortening of hospital stays, and isolation of infected patients. Molecular methods also have distinct advantages over conventional methods, including the ability to rapidly develop assays for emerging viruses and new variants of existing viruses, which is very helpful for infection control and epidemiological monitoring of pandemic viral respiratory infections. Clinicians should be familiar with test principles and performance characteristics, as well as collect and submit adequate specimens for molecular testing. Interpretive reports may be needed to assist those clinicians who are not familiar with molecular testing.

Molecular Niches in Detection and Identification of Specific Respiratory Viruses

For those most important viral pathogens (eg, influenza viruses and RSV), many reported feasibility studies have confirmed that molecular tests improve sensitivity of detecting potential pathogens from lower respiratory tract specimens as well as from respiratory swabs, and shorten the test turnaround time, thereby improving patient care [30-32]. The molecular assays will be used mainly to supplement rapid antigen testing and culture. For viral pathogens (eg, parainfluenza viruses, adenovirus, and enteroviruses), molecular assays have gradually been implemented as the mainstay. Molecular methods ensure appropriate early management and use of infection prevention and control procedures for vulnerable individuals, as well as differentiation between designated serotypes for epidemiological study [33, 34, 35•]. For the newly discovered respiratory viral pathogens (eg, hMPV, rhinoviruses, and coronaviruses), molecular assays have become the exclusive tool in the diagnostic algorithm [3638]. Molecular techniques also have resulted in discovery of novel respiratory viruses, such as human bocaviruses [2729, 39, 40], respiratory polyomaviruses [41, 42], and XMRV [43, 44], although their clinical relevance needs further investigation.

\section{Viral Respiratory Coinfections Identified}

by Molecular Methods

Molecular techniques can be designed in a monoplex (one target in one reaction) or a multiplex (multiple targets in one reaction) format. Recently available multiplex reverse transcriptase-PCR-based devices have led to identification of more viral respiratory coinfections than were previously recognized $[9 \bullet, 13 \bullet, 35 \bullet, 45,46 \bullet \cdot]$. Some studies have reported that multiple viruses can be detected using molecular methods in many institutional outbreaks of viral respiratory diseases [47, 48]. Commercially available devices, including ResPlex II (Qiagen),
MassTag PCR assay (Center for Infection and Immunity, Columbia University, New York, NY), RespiFinder assay (PathoFinder, Maastricht Area, The Netherlands), and FilmArray (Idaho Technology, Salt Lake City, UT), and several user-developed assays cover common respiratory viral and bacterial pathogens in one reaction. It has been reported that these coinfections are medically relevant and that effective treatment for severe respiratory tract infections will increasingly require diagnosis of all involved pathogens, as opposed to single-pathogen reporting $[9 \bullet, 13 \bullet, 35 \bullet, 45,46 \bullet \cdot]$. However, one study from The Netherlands indicated that implementation of multiple molecular assays for the etiologic diagnosis of lower respiratory tract infections increased the diagnostic yield considerably, yet did not reduce antibiotic use or costs [30]. Well-designed outcome studies are needed to further demonstrate the clinical relevance and cost effectiveness of simultaneous multipathogen detection and identification strategies for respiratory viral coinfections. Interpretive reports may be needed to assist the clinician in assessing such mixed infections.

\section{Quantification of Viral Respiratory Infections Using Molecular Methods}

The other distinct advantage of molecular techniques over conventional methods is the ability to quantify viral pathogens. Although qualitative molecular tests should only be used for diagnosis, viral load change in respiratory specimens can be used as an indication of "test of cure" for therapy monitoring. With implementation of the real-time technology, rapid and accurate viral load quantification by molecular assays is possible, which has proved useful in some clinical settings $[49,50]$. Real-time PCR assays have been reported for quantitative assessment of viral load in children naturally infected with RSV [51]. Multiplex, typespecific, real-time PCR assays have been reported for detection and quantification of respiratory adenoviruses $[34,52]$. Quantitative real-time PCR assays have been used to assess influenza A virus infections, including the pandemic A (H1N1) 2009 virus [53, 54], but no correlation was established between viral loads and clinical severity or duration of disease. Quantification of viral load may help clinicians predict disease progression, interpret the clinical relevance of multiple viral pathogens detected in the same sample, and monitor the efficacy of antiviral therapy.

Practical Importance of Molecular Methods in Prompt Diagnosis and Therapy Monitoring

Viral load data can provide important information regarding virus-host interaction, which is useful to predict disease severity and transmissibility in viral respiratory infections. Quantitative molecular assays make it possible to promptly 
establish the correlation between the viral load profile and clinical characteristics of viral respiratory infections, which would provide important knowledge for clinical management in terms of antiviral therapy and infection control measures. This has been supported by several recently published studies on the pandemic H1N1 2009 influenza A virus. Virological profile determined by quantitative RTPCR suggested that the prolonged viral shedding in young children and higher viral load in the stool had implications for formulating clinical management policies and infection control measures [55]. It was also reported that oral oseltamivir suppressed viral load more effectively and shortened the duration of viral shedding when given early in mild cases of pandemic $2009 \mathrm{H} 1 \mathrm{~N} 1$ infections [56, 57•].

Besides rapid detection of the pandemic variants and distinguishing these strains from circulating epidemic strains, identification of antiviral-resistant variants is equally important for pandemic surveillance and patient management. Rapid detection of oseltamivir resistance in severe pandemic H1N1 infections is essential for patients to receive maximum therapeutic benefit, and is useful for clinicians to allow for change to an effective treatment at a much earlier stage if resistance is found. Recent studies have reported the use of novel molecular methods to screen for the presence of the $\mathrm{H} 275 \mathrm{Y}$ resistance mutation in the neuraminidase gene [58-61]. In addition to accurate detection of the H275Y oseltamivirresistance allele, samples collected at multiple time points even showed a switch from wild-type oseltamivir-sensitive $275 \mathrm{H}$ to oseltamivir-resistant $275 \mathrm{Y}$ population after 9 days of treatment. In the light of emerging resistance, close monitoring and understanding of the nature and dynamics of resistance mutations in newly emerging strains should be a priority.

\section{Epidemiological Monitoring of Viral Respiratory Infections Using Molecular Methods}

Recent pandemic respiratory viral disease outbreaks in institutions present significant challenges for infection control and epidemiological monitoring. Serological tests still remain useful in epidemiological monitoring, whereas viral culture permits full identification and characterization of novel strains or emerging viruses, as well as determination of antiviral phenotypic susceptibility. The enhanced sensitivity and specificity of molecular methods have resulted in conventional methods now becoming secondary tiers in the triage of diagnostic options for investigating outbreaks and epidemiological studies. Molecular methods can also provide a much shorter test turnaround time to accurate results, which is vital for timely and effective intervention during an outbreak of pandemic viral respiratory infections. Molecular methods have been increasingly used in the molecular epidemiological studies of predominant etiological agents, such as influenza virus and RSV during seasonal epidemics [62-65].
These studies have demonstrated that the application of molecular methods can provide not only crucial epidemiological data, but also a more timely and accurate diagnosis of outbreaks, which allows for early symptomatic treatment, rational use of antibiotics, and improved infection control of epidemics. Recent studies have been reported to support the usefulness of molecular assays for implementation of a molecular monitoring system for endemic and epidemic viral respiratory infections or institutional outbreaks [66-69]. Multitargeted molecular assays are now becoming more cost-effective, with the increased cost of testing offset by a reduction in patient care cost due to an earlier diagnostic result provided by molecular methods. This economic advantage can be even more obvious for institutional outbreak and pandemic viral respiratory infections, in which time-to-result is of the most importance to prevent the spread of disease. However, well-defined outcome studies are still needed to determine the cost-effectiveness of these rapid molecular assays.

\section{Conclusions}

Nucleic acid-targeted molecular techniques enhance diagnostic sensitivity and specificity, shorten test turnaround time, and provide automatic and high-throughput processing for the identification of viral pathogens causing respiratory tract infections. In-house and commercially available molecular methods have been increasingly used to detect and identify common respiratory viruses as well as recently identified pathogens. As techniques have advanced, a panel of viral pathogens now can be qualitatively and quantitatively detected in a single reaction, which significantly enhances diagnostic efficacy and yield. Implementation of molecular tests for the diagnosis of respiratory viral infections is limited by technical complexity, costs, and lack of proper validation and standardization of assays. The performance characteristics and limitations of these molecular tests must be clearly understood by laboratory personnel and clinicians to ensure proper utilization and interpretation. Prompt exchange of relevant information between the clinician and the laboratory is essential for the molecular diagnosis of viral respiratory infections. Moreover, interpretive reports may play a role, because mixed infections occur frequently.

Acknowledgments The authors thank Dr. Charles Stratton for critically reviewing the manuscript. The project was supported in part by the China Key Technologies Research and Development Program for Infectious Diseases (2009ZX10004-104) and by the Vanderbilt CTSA grant from NCRR/National Institutes of Health (UL1RR024975).

Disclosure Conflicts of interest: S. Zhang-none; W. Zhang-none; Y-W. Tang is a consultant of Ibis Biosciences/Abbott Molecular. 


\section{References}

Papers of particular interest, published recently, have been highlighted as:

- Of importance

•- Of major importance

1. Barenfanger J, Drake C, Leon N, et al. Clinical and financial benefits of rapid detection of respiratory viruses: an outcomes study. J Clin Microbiol. 2000;38:2824-8.

2. Woo PC, Chiu SS, Seto WH, Peiris M. Cost-effectiveness of rapid diagnosis of viral respiratory tract infections in pediatric patients. $\mathrm{J}$ Clin Microbiol. 1997;35:1579-81.

3. Ginocchio CC. Detection of respiratory viruses using nonmolecular based methods. J Clin Virol. 2007;40 Suppl 1:S11-4.

4. - Fox JD. Nucleic acid amplification tests for detection of respiratory viruses. J Clin Virol. 2007;40(Suppl 1):S15-S23. This is a good review article covering current molecular techniques for respiratory virus detection and identification.

5. - Wu W, Tang YW. Emerging molecular assays for detection and characterization of respiratory viruses. Clin Lab Med. 2009;29:67393. This is a good review article covering current methods and predicting future molecular techniques for respiratory virus detection and identification.

6. Fan J, Henrickson KJ, Savatski LL. Rapid simultaneous diagnosis of infections with respiratory syncytial viruses A and B, influenza viruses $A$ and $B$, and human parainfluenza virus types 1,2 , and 3 by multiplex quantitative reverse transcription-polymerase chain reaction-enzyme hybridization assay (Hexaplex). Clin Infect Dis. 1998;26:1397-402.

7. Legoff J, Kara R, Moulin F, et al. Evaluation of the one-step multiplex real-time reverse transcription-PCR ProFlu-1 assay for detection of influenza $\mathrm{A}$ and influenza $\mathrm{B}$ viruses and respiratory syncytial viruses in children. J Clin Microbiol. 2008;46:789-91.

8. Liao RS, Tomalty LL, Majury A, Zoutman DE. Comparison of viral isolation and multiplex real-time reverse transcription-PCR for confirmation of respiratory syncytial virus and influenza virus detection by antigen immunoassays. J Clin Microbiol. 2009;47: 527-32.

9. • Mahony J, Chong S, Merante F, et al. Development of a respiratory virus panel test for detection of twenty human respiratory viruses by use of multiplex PCR and a fluid microbead-based assay. J Clin Microbiol. 2007;45:2965-70. This article describes the first FDAapproved multiplex RT-PCR assay to detect and identify a panel of clinically encountered respiratory viruses.

10. Merante F, Yaghoubian S, Janeczko R. Principles of the xTAG respiratory viral panel assay (RVP Assay). J Clin Virol. 2007;40 Suppl 1:S31-5.

11. Pabbaraju K, Tokaryk KL, Wong S, Fox JD. Comparison of the Luminex XTAG respiratory viral panel with in-house nucleic acid amplification tests for diagnosis of respiratory virus infections. J Clin Microbiol. 2008;46:3056-62.

12. Marshall DJ, Reisdorf E, Harms G, et al. Evaluation of a multiplexed PCR assay for detection of respiratory viral pathogens in a public health laboratory setting. J Clin Microbiol. 2007;45:3875-82.

13. - Li H, McCormac MA, Estes RW, et al. Simultaneous detection and high-throughput identification of a panel of RNA viruses causing respiratory tract infections. J Clin Microbiol. 2007;45:2105-9. This is one of the articles demonstrating that multiplex PCR assays enhanced diagnostic yields.

14. Nolte FS, Marshall DJ, Rasberry C, et al. MultiCode-PLx system for multiplexed detection of seventeen respiratory viruses. J Clin Microbiol. 2007;45:2779-86.
15. Raymond F, Carbonneau J, Boucher N, et al. Comparison of automated microarray detection with real-time PCR assays for detection of respiratory viruses in specimens obtained from children. J Clin Microbiol. 2009;47:743-50.

16. Belak S, Kiss I, Viljoen GJ. New developments in the diagnosis of avian influenza. Rev Sci Tech. 2009;28:233-43.

17. Schlingemann J, Leijon M, Yacoub A, et al. Novel means of viral antigen identification: improved detection of avian influenza viruses by proximity ligation. J Virol Methods. 2010;163:116-22.

18. He J, Bose ME, Beck ET, et al. Rapid multiplex reverse transcription-PCR typing of influenza $\mathrm{A}$ and $\mathrm{B}$ virus, and subtyping of influenza A virus into H1, 2, 3, 5, 7, 9, N1 (human), $\mathrm{N} 1$ (animal), N2, and N7, including typing of novel swine origin influenza A (H1N1) virus, during the 2009 outbreak in Milwaukee, Wisconsin. J Clin Microbiol. 2009;47:2772-8.

19. Mahony JB, Hatchette T, Ojkic D, et al. Multiplex PCR tests sentinel the appearance of pandemic influenza viruses including H1N1 swine influenza. J Clin Virol. 2009;45:200-2.

20. Gyarmati P, Metreveli G, Kecskemeti S, et al. Molecular analysis and characterization of swine and human influenza viruses isolated in Hungary in 2006-2007. Virus Genes 2009.

21. Lam WY, Leung TF, Lee $\mathrm{N}$, et al. Development and comparison of molecular assays for the rapid detection of the pandemic influenza A (H1N1) 2009 virus. J Med Virol. 2010;82:675-83.

22. Hindiyeh M, Hillyard DR, Carroll KC. Evaluation of the Prodesse Hexaplex multiplex PCR assay for direct detection of seven respiratory viruses in clinical specimens. Am J Clin Pathol. 2001;116:218-24.

23. van Elden LJ, van Loon AM, van der Beek A, et al. Applicability of a real-time quantitative PCR assay for diagnosis of respiratory syncytial virus infection in immunocompromised adults. J Clin Microbiol. 2003;41:4378-81.

24. •- Mahony JB. Detection of respiratory viruses by molecular methods. Clin Microbiol Rev. 2008;21:716-47. This is a good review article that covers state-of-the-art molecular techniques in detection of respiratory viruses.

25. Loens K, Goossens H, de Laat C, et al. Detection of rhinoviruses by tissue culture and two independent amplification techniques, nucleic acid sequence-based amplification and reverse transcription-PCR, in children with acute respiratory infections during a winter season. J Clin Microbiol. 2006;44:166-71.

26. Lee WM, Grindle K, Pappas T, et al. High-throughput, sensitive, and accurate multiplex PCR-microsphere flow cytometry system for large-scale comprehensive detection of respiratory viruses. J Clin Microbiol. 2007;45:2626-34.

27. Lu X, Chittaganpitch M, Olsen SJ, et al. Real-time PCR assays for detection of bocavirus in human specimens. J Clin Microbiol. 2006;44:3231-5.

28. Neske F, Blessing K, Tollmann F, et al. Real-time PCR for diagnosis of human bocavirus infections and phylogenetic analysis. J Clin Microbiol. 2007;45:2116-22.

29. Choi JH, Chung YS, Kim KS, et al. Development of real-time PCR assays for detection and quantification of human bocavirus. J Clin Virol. 2008;42:249-53.

30. Oosterheert JJ, van Loon AM, Schuurman R, et al. Impact of rapid detection of viral and atypical bacterial pathogens by real-time polymerase chain reaction for patients with lower respiratory tract infection. Clin Infect Dis. 2005;41:1438-44.

31. Falsey AR, Formica MA, Walsh EE. Diagnosis of respiratory syncytial virus infection: comparison of reverse transcription-PCR to viral culture and serology in adults with respiratory illness. J Clin Microbiol. 2002;40:817-20.

32. Gooskens J, Swaan CM, Claas EC, Kroes AC. Rapid molecular detection of influenza outbreaks in nursing homes. J Clin Virol. 2008;41:7-12. 
33. Lin B, Vora GJ, Thach D, et al. Use of oligonucleotide microarrays for rapid detection and serotyping of acute respiratory disease-associated adenoviruses. J Clin Microbiol. 2004;42:3232-9.

34. Metzgar D, Gibbins C, Hudson NR, Jones MS. Evaluation of multiplex type-specific real-time PCR assays using the LightCycler and joint biological agent identification and diagnostic system platforms for detection and quantitation of adult human respiratory adenoviruses. J Clin Microbiol. 2010;48:1397403.

35. - Peng D, Zhao D, Liu J, et al. Multipathogen infections in hospitalized children with acute respiratory infections. Virol J. 2009;6:155. These authors demonstrated that multiplex PCR assays enhanced diagnostic yields.

36. McErlean P, Shackelton LA, Andrews E, et al. Distinguishing molecular features and clinical characteristics of a putative new rhinovirus species, human rhinovirus $\mathrm{C}$ (HRV C). PLoS One. 2008;3:e1847.

37. Scheltinga SA, Templeton KE, Beersma MF, Claas EC. Diagnosis of human metapneumovirus and rhinovirus in patients with respiratory tract infections by an internally controlled multiplex real-time RNA PCR. J Clin Virol. 2005;33:306-11.

38. van Elden LJ, van Loon AM, van Alphen F, et al. Frequent detection of human coronaviruses in clinical specimens from patients with respiratory tract infection by use of a novel real-time reverse-transcriptase polymerase chain reaction. J Infect Dis. 2004; 189:652-7.

39. Allander T, Tammi MT, Eriksson M, et al. Cloning of a human parvovirus by molecular screening of respiratory tract samples. Proc Natl Acad Sci U S A. 2005;102:12891-6.

40. Song JR, Jin Y, Xie ZP, et al. Novel human bocavirus in children with acute respiratory tract infection. Emerg Infect Dis. 2010;16:324-7.

41. Wattier RL, Vazquez M, Weibel C, et al. Role of human polyomaviruses in respiratory tract disease in young children. Emerg Infect Dis. 2008;14:1766-8.

42. Gaynor AM, Nissen MD, Whiley DM, et al. Identification of a novel polyomavirus from patients with acute respiratory tract infections. PLoS Pathog. 2007;3:e64.

43. Lombardi VC, Ruscetti FW, Das Gupta J, et al. Detection of an infectious retrovirus, XMRV, in blood cells of patients with chronic fatigue syndrome. Science. 2009;326:585-9.

44. Fischer N, Schulz C, Stieler K, et al. Xenotropic murine leukemia virus-related gammaretrovirus in respiratory tract. Emerg Infect Dis. 2010;16:1000-2.

45. Brunstein J, Thomas E. Direct screening of clinical specimens for multiple respiratory pathogens using the Genaco Respiratory Panels 1 and 2. Diagn Mol Pathol. 2006;15:169-73.

46. •• Brunstein JD, Cline CL, McKinney S, Thomas E. Evidence from multiplex molecular assays for complex multipathogen interactions in acute respiratory infections. J Clin Microbiol. 2008;46:97-102. The data presented in this study reveal that multiple infections of respiratory viral pathogens are frequent and provide evidence for complex interactions between different infectious agents. The clinical relevance of respiratory virus coinfections is also addressed.

47. Eshaghi A, Blair J, Burton L, et al. Characterization of an influenza $\mathrm{A}$ and influenza $\mathrm{B}$ co-infection of a patient in a longterm care facility with co-circulating influenza A and influenza B. Int J Infect Dis. 2009;13:e127-8.

48. Echavarria M, Maldonado D, Elbert G, et al. Use of PCR to demonstrate presence of adenovirus species $\mathrm{B}, \mathrm{C}$, or $\mathrm{F}$ as well as coinfection with two adenovirus species in children with flu-like symptoms. J Clin Microbiol. 2006;44:625-7.

49. Lassauniere R, Kresfelder T, Venter M. A novel multiplex realtime RT-PCR assay with FRET hybridization probes for the detection and quantitation of 13 respiratory viruses. J Virol Methods. 2010;165:254-60.

50. Kaltenboeck B, Wang C. Advances in real-time PCR: application to clinical laboratory diagnostics. Adv Clin Chem. 2005;40:21959.

51. Gerna G, Campanini G, Rognoni V, et al. Correlation of viral load as determined by real-time RT-PCR and clinical characteristics of respiratory syncytial virus lower respiratory tract infections in early infancy. J Clin Virol. 2008;41:45-8.

52. Shike H, Shimizu C, Kanegaye J, et al. Quantitation of adenovirus genome during acute infection in normal children. Pediatr Infect Dis J. 2005;24:29-33.

53. Boivin G, Coulombe Z, Wat C. Quantification of the influenza virus load by real-time polymerase chain reaction in nasopharyngeal swabs of patients treated with oseltamivir. J Infect Dis. 2003;188:578-80.

54. Duchamp MB, Casalegno JS, Gillet Y, et al. Pandemic A(H1N1) 2009 influenza virus detection by real time RT-PCR: is viral quantification useful? Clin Microbiol Infect. 2010;16:317-21.

55. To KK, Chan KH, Li IW, et al. Viral load in patients infected with pandemic H1N1 2009 influenza A virus. J Med Virol. 2010;82:1-7.

56. Li IW, Hung IF, To KK, et al. The natural viral load profile of patients with pandemic 2009 influenza $\mathrm{A}(\mathrm{H} 1 \mathrm{~N} 1)$ and the effect of oseltamivir treatment. Chest. 2010;137:759-68.

57. - Ling LM, Chow AL, Lye DC, et al. Effects of early oseltamivir therapy on viral shedding in 2009 pandemic influenza A (H1N1) virus infection. Clin Infect Dis. 2010;50:963-9. This study demonstrated effects of early antiviral efficacy by using molecular techniques.

58. van der Vries E, Jonges M, Herfst S, et al. Evaluation of a rapid molecular algorithm for detection of pandemic influenza $\mathrm{A}$ (H1N1) 2009 virus and screening for a key oseltamivir resistance (H275Y) substitution in neuraminidase. J Clin Virol. 2010;47: 34-7.

59. Wang B, Dwyer DE, Blyth CC, et al. Detection of the rapid emergence of the $\mathrm{H} 275 \mathrm{Y}$ mutation associated with oseltamivir resistance in severe pandemic influenza virus A/H1N1 09 infections. Antiviral Res. 2010;87:16-21.

60. Mehta T, McGrath E, Bheemreddy S, et al. Detection of oseltamivir resistance during treatment of 2009 H1N1 influenza virus infection in immunocompromised patients: utility of cycle threshold values of qualitative real-time reverse transcriptase PCR. J Clin Microbiol. 2010;48:4326-8.

61. Mahony JB, Chong S, Luinstra K, et al. Development of a novel bead-based multiplex PCR assay for combined subtyping and oseltamivir resistance genotyping $(\mathrm{H} 275 \mathrm{Y})$ of seasonal and pandemic H1N1 influenza A viruses. J Clin Virol 2010;49:27782.

62. Jalal H, Bibby DF, Bennett J, et al. Molecular investigations of an outbreak of parainfluenza virus type 3 and respiratory syncytial virus infections in a hematology unit. J Clin Microbiol. 2007;45:1690-6.

63. Visser A, Delport S, Venter M. Molecular epidemiological analysis of a nosocomial outbreak of respiratory syncytial virus associated pneumonia in a kangaroo mother care unit in South Africa. J Med Virol. 2008;80:724-32.

64. Agrawal AS, Sarkar M, Chakrabarti S, et al. Comparative evaluation of real-time PCR and conventional RT-PCR during a 2 year surveillance for influenza and respiratory syncytial virus among children with acute respiratory infections in Kolkata, India, reveals a distinct seasonality of infection. J Med Microbiol. 2009;58:1616-22.

65. Caram LB, Chen J, Taggart EW, et al. Respiratory syncytial virus outbreak in a long-term care facility detected using reverse transcriptase polymerase chain reaction: an argument for realtime detection methods. J Am Geriatr Soc. 2009;57:482-5. 
66. Wang W, Cavailler P, Ren $\mathrm{P}$, et al. Molecular monitoring of causative viruses in child acute respiratory infection in endemoepidemic situations in Shanghai. J Clin Virol. 2010;49:211-8.

67. Lau LL, Cowling BJ, Fang VJ, et al. Viral shedding and clinical illness in naturally acquired influenza virus infections. J Infect Dis. 2010;201:1509-16.
68. van de Pol AC, Rossen JW, Wolfs TF, et al. Transmission of respiratory syncytial virus at the paediatric intensive-care unit: a prospective study using real-time PCR. Clin Microbiol Infect. 2010;16:488-90.

69. Fairchok MP, Martin ET, Chambers S, et al. Epidemiology of viral respiratory tract infections in a prospective cohort of infants and toddlers attending daycare. J Clin Virol. 2010;49:16-20. 